Medical Reference Services Quarterly. 2008. Vol. 27, no. 4, p. 367-378.

Print ISSN: 0276-3869 Online ISSN: 1540-9597

DOI: $10.1080 / 02763860802367755$

http://www.tandf.co.uk/journals/WMRS

http://dx.doi.org/10.1080/02763860802367755

(C) 2008 by The Haworth Press. All rights reserved.

\title{
Single Service Point: It's All in the Design
}

\section{Pamela S. Bradigan, Ruey L. Rodman}

\begin{abstract}
Design thinking" principles from a leading design firm, IDEO, were key elements in the planning process for a one-desk service model, the ASK Desk, at the John A. Prior Health Sciences Library. The library administration and staff employed the methodology to enhance customer experiences, meet technology challenges, and compete in a changing education environment. The most recent renovations demonstrate how the principles were applied. The concept of "continuous design thinking" is important in the library's daily operations to serve customers most effectively.
\end{abstract}

\section{INTRODUCTION AND HISTORY}

The Ohio State University John A. Prior Health Sciences Library (PHSL) has been on a design journey since the current facility was built in 1972. This article describes the process of creating a single service point called the ASK Desk. The original five-story building was constructed around a two-story high Randtriever, an automated device, located on the second and third floors, that was used to store and retrieve materials. ${ }^{1}$ Basic library services were provided in two locations. Circulation services were located adjacent to the Randtriever on the third floor. Librarians provided mediated database searching and reference services at a desk on the second floor. The first floor, where customers entered the building, was an open area with a grand staircase.

The PHSL administration initiated plans to renovate the entire building in the early 1990s due, in part, to the need to remove the chronically malfunctioning Randtriever. The renovation planning team and architect designed a facility that included:

1. an enclosed first floor, formerly an open air space with grand stair case, which added 12,546 gross square footage to library space;

2. removal of the Randtriever from the second and third floors, which provided for more flexible space;

3. new compact shelving, 50-seat computer lab, and a 40-seat classroom on the fourth floor; and

4. an archives/rare book facility and large meeting room on the fifth floor.

The renovation began in 1995 and was completed in 1996. The result was an open design that allowed for flexibility in study spaces and service desks. This renovation maintained two service points. Circulation and reference were now on the "newly enclosed"' first floor but 
separated by waist-high book stacks for the reference collection.

The administration initiated a partial first-floor renovation in 2004 to change the library's service model and to incorporate a new emphasis on information and technology services. Several OSU College of Medicine (COM) technology units, which collectively became the Center for Knowledge Management (CKM), began to partner with the library to provide enhanced resources and services. The scope of the first-floor renovation included the consolidation of the circulation and reference desks into the ASK Desk, a Do-it-Yourself technology area, a Copyright Management Office, and a Medical Center Information Services (IS) (providing desk-top computer support and service for hospital pagers) window across from the one service desk. Offices were built on the fourth floor to house the CKM staff, and the computer lab was renovated and re-equipped to seat 80. Also at about this time, the COM's Clinical Skills Education and Assessment Center moved into the basement of the library. This renovation, focusing on the Ask Desk, was completed in late 2004.

Three years later, in 2007, the first floor was renovated once again. More reference resources had become available in online form and the print reference collection was weeded and reduced to one range of shelves. This increased the open space on the first floor for more collaborative seating and computer workstations. Plans are now underway for a coffee bar to replace a small consumer health collection on the first floor that had been established in the 1996 renovation. That collection was moved to a more strategic location in a family waiting area of the OSU hospitals.

\section{LITERATURE REVIEW}

For the purposes of this paper the authors reviewed the literature in three areas: the consolidated service point, project management, and library renovations. The idea of a consolidated service point has been written about extensively in the literature over the past 15 years. As a model for service delivery in the academic library, it has also been called the information commons, learning spaces, as well as the single service desk. Whatever term is used, it is indicative of a shift from print to digital formats, from traditional to online technologies, and from shelves of books to collaborative physical environments.

From the article "University of Iowa Opens Info Commons" that appeared in C\&RL News, October 1996, to the most recent "Information Commons to Go" that appeared in Computers in Libraries, March 2008, there is no shortage of information on the information commons, as it has transformed libraries from multiple service points to streamlined one-stop shopping centers. ${ }^{2-5}$ Sinclair claims that the commons is a natural extension of a library's traditional mission in a wired world. ${ }^{6}$ Beagle states:

The Information Commons creates a synergy between the user support skills of computer staff, the information skills of reference staff, and production skills of media staff. Physically, it offers the flexible work space all staff need to apply their combined expertise adaptively to the rapidly changing needs of a highly demanding user community. ${ }^{7}$

In the library literature, project management is defined primarily as systems and technology projects. Most information on project management is found in business and computer journal literature. Industry and business have indicated that college graduates should be well-versed in collaborative problem solving and general project management concepts as well as 
having good technical skills. ${ }^{8}$ Organizations may undertake projects to create unique products or services. As Lierni and Ribiere state, 'Project management is the application of 'knowledge,' skills, tools, and techniques to project activities to meet project requirements." 9 Project management implies a certain level of collaboration to accomplish a mission and support the outlined strategy. ${ }^{10}$ Library renovations projects readily fall into using project management techniques.

There are many articles in the literature that describe various renovation projects. These reports discuss area makeovers, complete building renovations, selecting and using temporary locations, and include all types of libraries. No matter the size of the project, it must be planned, questions answered, and implemented. As Branin states, "The answers are to be found through an exploration of emerging library practices of 'content management' and 'learning space design' that must be linked to the aesthetics and functionality of effective architecture." ${ }^{11}$ Learning spaces supported by consolidated services and staff are the currently accepted practice for libraries. What follows is a review of the planning process for the most recent renovations at the PHSL, focusing on the consolidated services model.

\section{DESIGN PRINCIPLES}

According to Steven J. Bell, “A design approach to the delivery of outstanding services can help library professionals become strategizers and problem-solvers who put the user experience first.", 12 The PHSL staff embraced "design thinking', when planning both renovations of the first floor. Tom Kelley, founder and general manager of IDEO, a leading design firm, identifies five steps in the "design thinking" process: understand, observe, visualize, evaluate/refine, and implement. ${ }^{13}$

\section{Step One: Understand}

A critical first step is to understand the needs and challenges of the library customer, including their perceptions of offered services and products. This understanding needs to be linked to the renovation goal. Jacoby and Rodriguez state, "Innovation loves structure. . . But design thinkers are inspired by constraints, which provide the focus to do generative work in the face of great complexity." "14 By their nature, libraries are highly structured organizations and offer structured products and services. As early users of complex technology systems, libraries and librarians have been and still are on the cutting edge of technological advancements in information structure and communication.

The user population or library customer is continuously changing. Their needs are varied, too. Jacoby and Rodriguez further state, "You must uncover human needs to design compelling user value propositions." "14 In redesigning the PHSL, goals were to streamline services (one-stop shopping) and to provide technological tools so that customers could best manage their information management needs. Kelley believes understanding what people want, building a prototype, and then asking the people who will use it and what they think, is key. ${ }^{13}$ 


\section{Step Two: Observe}

Observing what customers are doing, what they need, and how the physical environment of the building works for them is the next step in design thinking. The library staff saw the need to support students and faculty more effectively in the way they learn and work. The librarians noted health sciences curriculum changes that incorporated problem-based learning, original research, and collaborative projects. The frequent use of skeletons and anatomical models, and the proliferation of electronic resources and new tools such as PDAs and laptop computers, were considered in designing new space and services. Library customers, both faculty and students, also requested guidance about copyright law to support their teaching and learning activities. The identification and articulation of their needs and challenges were important elements in the design process. According to Tim Brown, "Regardless of whether your goal is to innovate around a product, service, or business opportunity, you get good insights by having an observant and empathetic view of the world." 15

There were several ways in which PHSL library staff documented what customers were using and what tools they needed. If customers were waiting in a line for a specific service or resource, this indicated that a particular service or tool was in demand, and steps were taken to make it more available. Staff were trained to observe and identify ways to continuously improve services. Customer input was gathered from LibQUAL, informal surveys, written suggestions, the Library Advisory Committee, and student organizations. Customers requested more group or collaborative space, additional workstations, mobile anatomical models, moveable or flexible seating, and easy access to electricity outlets. These observations, as well as input from customer surveys and focus groups, led directly to the next step: visualization.

\section{Step Three: Visualize}

The third step of the IDEO method of design planning is to visualize how library customers could have improved experiences in the library. Kelley and Littman state, "Visualize new-to-the world concepts and the customers who will use them. Some people think of this step as predicting the future, and it is probably the most brain-storming intensive phase of the process." ${ }^{, 13}$ Another way to think about this is to consider how the library could create a memorable customer experience, or what would bring the customer back to the library again and again.

The staff consulted with design experts and challenged themselves to think creatively about current customers and their needs and think beyond the traditional academic library commodities such as books, journals, and study space. During brainstorming sessions, the staff imagined resources and methods to overcome some observed and customer-noted barriers. One of these sessions was especially memorable, when staff members created small posters to illustrate their ideas. The posters were created by cutting out images found in magazines. Some ideas generated were: roving reference, electronic message board, IM support, wireless network, podcasts of services and resources, and more comfortable furniture including built-in access for mobile devices.

Upon completion of the visualization of the new space and services, agreed upon ideas and concepts were sent to the architect for an initial design. The library administration selected the same architect who had managed the complete renovation of the PHSL in the 1990s. Library and CKM staff provided recommendations and renovation ideas to the architect, who listened and 
responded to questions. Since the architect was familiar with the building, he provided design suggestions that were compatible with the building structure. He then created a series of drawings that included his recommendations about how to incorporate the library staff's observations, ideas, and suggestions.

\section{Step Four: Evaluate/Refine}

Upon receipt of the architectural plans, staff began to evaluate the initial efforts and make changes. Steps three and four became a continuous circle of events as plans were amended and then returned for more evaluation. Time spent getting input from staff, customers, and people outside the project are invaluable at this stage. The architectural plans were posted in the staff lounge and all staff asked to review and make comments or suggestions. A formal presentation was given at a staff meeting to gather more input. The overall goals in this step are to improve the original design, answer any questions, and get buy-in from the staff on the finished plans.

\section{Step Five: Implement}

Putting all the pieces together and going public with the ASK Desk was exciting and also somewhat frightening, since the traditional model of separate circulation and reference desks was being changed. To illustrate how the library employed "design thinking," the 2004 implementation process will be described in detail with occasional references to the 2007 redesign.

To move from the vision to reality, a task force of seven members was established with a clear charge. Representatives and expertise from the Library and CKM worked for approximately three months to write and submit a plan for the overall project. An implementation team was then formed that worked with a budget of \$100,000 to implement the 2004 ASK Desk and first-floor redesign. The team was headed by experienced leaders who employed strong organizational skills, constantly referred to the new desk vision, and utilized architectural and professional library design expertise. In order to streamline the implementation of the ASK Desk and the first floor plans, the team identified four strategic areas of concentration: (1) physical space, (2) service models, (3) software/technology enhancements, and (4) staff communications and education.

The implementation team used the Task Force report to develop a staffing model for newly expanded services, a staff training program, and a communication plan. They also employed a variety of methods to keep the momentum moving forward towards the actual construction phase. Often subsets of the larger group met separately to handle time-consuming or complex matters and brought their recommendations back to the larger group for implementation. With the assistance of the entire staff, the team developed a matrix of customer services offered by the Library and CKM to identify duplication or overlap. Figure 1 shows the matrix developed for Education \& Consultation Services. The matrix outlined the Library and CKM. Emphasis was on combining efficiencies of both departments with a new customer experience in renovated space.

Newly generated ideas were incorporated and service gaps were remedied in the 2004 redesign of the PHSL. For example, the ASK Desk offered information, circulation, and portable computer services on the front line. The service plan incorporated referrals to a reference librarian stationed at a separate section of the ASK Desk. Examples of remedies for "gaps" were creating a 
computer commons area, providing copyright expertise, and including a service window and staffing for hospital pager and remote computer assistance. The architects, working in conjunction with the team, identified areas that might be downsized, or rehabilitated and reused. For example, the photocopier facilities became smaller due to the decrease in copying, and the old reference desk was reused to construct the ASK Desk.

The physical location of the ASK Desk, directly in front of the customers when entering the building, supported the one-stop model for services. The desk is now a centralized service point for in-person, telephone, e-mail, and instant message queries; circulation, information, and reference functions; and PDA, laptop and wireless support. Customers also pick up fee-based products such as posters that are created by the CKM's medical illustrators, artists, and designers.

Front-line ASK Desk staff are proactive in assisting customers and have backup staffing as needed. The reference desk is located behind the ASK Desk, and customers with reference questions are referred to the librarian as needed. The "tiered" reference service, with its close physical proximity to staff, has resulted in a seamless customer service model. The ASK Desk, staffed during all hours the Library is open, has a staffing model based upon the need for a consistent level of service to meet baseline customer needs, along with added expertise during hours of greatest demand. The model is periodically reviewed to ascertain if it is continuing to meet customer needs.

FIGURE 1. Education and Consultation Services Matrix

\begin{tabular}{|l|l|}
\hline Overlap & Management of technology-based projects \\
\hline Overlap & Development and deployment strategies \\
\hline Overlap & $\begin{array}{l}\text { Assistance on technology needs, institutional } \\
\text { infrastructure and technical elements required when } \\
\text { developing educational technology grants }\end{array}$ \\
\hline CKM & $\begin{array}{l}\text { Assistance with e-learning management systems, } \\
\text { advanced software tools and technologies }\end{array}$ \\
\hline CKM & $\begin{array}{l}\text { HIPAA services for academic areas/College of } \\
\text { Medicine and Public Health (including medical } \\
\text { students) }\end{array}$ \\
\hline Overlap & Application instruction in classrooms and one-to-one \\
\hline Overlap & Development of resources for customers \\
\hline Overlap & Documentation and articles development \\
\hline Overlap & $\begin{array}{l}\text { Technical presentations and overviews for technical } \\
\text { and non-technical sessions/meetings (including CE } \\
\text { sessions) }\end{array}$ \\
\hline Library & Course specific research presentations \\
\hline Library & For credit courses \\
\hline Library & Workshops \\
\hline Library & Development of tutorials and tip sheets \\
\hline
\end{tabular}


A small Medical Center IS service window is positioned across from the ASK Desk. The computer commons area is also near the ASK Desk, and the Copyright Management Office is available nearby. The close proximity of the computer area (the "Do It Yourself' or DIY computer commons) to the ASK Desk encourages customers to experiment with high-end computers loaded with multimedia and productively software, scanners, card readers, and PDA synching stations. The computer commons area was recently expanded in 2007 from eight workstations to sixteen by removing printed reference stacks. This reuse of the stacks area illustrates the ongoing efforts to renovate in order to meet customer needs.

During the planning stages, the task force initiated Library Web site enhancements to complement the physical changes. The implementation team developed a feature of the Web site called "How Do I'" to provide answers to commonly asked questions about the Library, CKM, and the Medical Center. The database incorporated a great deal of information about the new service model, which was useful to staff as well as customers. For example, a couple of frequently asked questions that customers can now find online answers for are:

1. How do I have a poster made?

Make the poster file in PowerPoint, then upload the PowerPoint file to us through our Web site's file transfer page.

Be sure to follow the instructions on the file transfer page and call us at 292-8034, after uploading the file and give us your name, the poster file name and your telephone/pager number. We will make a small proof and then call you when the proof is ready to look at. The first proof is free; any subsequent ones are $\$ 10.00$ each.

The normal turnaround time for a poster job is about 3 days. Lamination and/or mounting for a poster add 1 to $11 / 2$ days to turnaround time.

http://ckm.osu.edu/print/5034.cfm (poster tutorial)

2. How do I find a database for my medical subject?

Use these quick links to go directly to a particular subject area or browse the full list below:

- Biomedical Research . Clinical Medicine . Drug Information . Mental Health

- Multidisciplinary

- New Technology/Product Use

- Nursing/Allied Health

- Patient Education

- All OSU Databases

Regular updates on the progress of the project were included at monthly staff meetings. Particular attention was paid to the public services staff who heard regular updates at their unit meetings, and they were often called upon to provide input as the planning progressed. Several weeks before the ASK Desk opened, an implementation team member was appointed as a staff project manager along with an instruction librarian (not on the implementation team) to develop training materials and provide extensive staff training on the new service model, new Web site tools, and DIY workstation components.

The inauguration of the ASK Desk took place at the beginning of a new academic quarter. Most of the construction took place over a long break between quarters so as not to disrupt 
services. The opening was celebrated with an official ribbon-cutting ceremony, which was well promoted and attended by customers, guests, and staff.

\section{CONCLUSION}

The renovation experiences at the PHSL illustrate some trends: (1) redesign frequency at the PHSL is increasing; (2) continuous 'design thinking', is important in the daily operations of the Library to serve customers most efficiently; (3) proactive solicitation of ideas and brainstorming are valuable; and (4) dramatic changes in the education setting and technology continue to influence the Library's services and resources. At the PHSL, the consolidated services model has resulted in an increase in customer satisfaction and input on value-added services. For example, building usage has increased $19.8 \%$ since the initial renovation in 2004; the student government representative praised the Library for the student involvement in decision making; and customers are proactively voicing opinions on topics such as a coffee/snack bar and library furniture. Seaman aptly notes that space planning should be "user-based and focused on learning impacts rather than traditional library services." ${ }^{16}$ Continuous updates and enhancements to the consolidated service model can be made effectively by using IDEO's "design thinking' concepts: understand, observe, visualize, evaluate, and implement.

\section{REFERENCES}

1. Van Brimmer, B., and Sawyers, E. “'The Randtriever: Its Use at the Ohio State University." Library Hi Tech 8, no. 3 (1990): 71-81.

2. Lippincott, J.K. “New Library Facilities: Opportunities for Collaboration.' Resource Sharing \& Information Networks 17, no. 1-2 (2004): 147-57.

3. Gohlke, M.J., and Ray, K. "Impacts of an Information Commons on an Academic Library's Service Points.' Journal of Access Services 1(2003): 57-71.

4. Gayton, J. T. “Academic Libraries: Social or Communal? The Nature and Future of Academic Libraries." The Journal of Academic Librarianship 34, no. 1 (2008): 60-6.

5. Spencer, M.E. ' Evolving a New Model: The Information Commons.' Reference Services Review 34, no. 2 (2006): 242-7.

6. Sinclair, B. "Commons 2.0: Library Spaces Designed for Collaborative Learning.' Educause Quarterly 4(2007): 4-6.

7. Beagle, D. 'CConceptualizing and Information Commons.', The Journal of Academic Librarianship 25, no. 2 (1999): 82-9.

8. Smith, H., Smarkusky, S., and Corrigall, E. “Defining Projects to Integrate Evolving Team Fundamentals and Project Management Skills.” Journal of Information Systems Education 19(Spring 2008): 99-110.

9. Lierni, P.C., and Ribiere, V.M. "The Relationship Between Improving the Management of Projects and the Use of KM." The Journal of Information and Knowledge Management Systems 38, no. 1 (2008): 133-46.

10. Nosek, J.T., and McManus, M. “Collaboration Challenges: Bridging the IT Support Gap." Information Systems Management 25, no. 1 (2008): 3-7.

11. Branin, J.J. "Shaping Our Space: Envisioning the New Research Library." Journal of Library Administration 46, no. 2 (2007): 27-53.

12. Bell, S.J. “Design Thinking.” American Libraries 39, no. 1-2 (January/ February 2008): 44-9.

13. Kelley, T., and Littman, J. The Art of Innovation: Lessons in Creativity from IDEO, American's Leading Design Firm. New York: Currency/Doubleday, 2001

14. Jacoby, R., and Rodriguez, D. "Innovation, Growth, and Getting to Where You Want to Go." Design Management Review 18, no. 1 (2007): 10-5. 
15. Brown, T. "Strategy by Design." Fast Company no. 95 (June 2005): 52-4.

16. Seaman, S. "The Library as Learning Environment: Space Planning in an Academic Library." Colorado Libraries 32, no. 1 (2006): 5-7. 